\title{
A review on Fabrication Methods and Analysis of Mechanical Properties of Metal Foams
}

\author{
Ali Nawaz ${ }^{1}$, Sushila Rani ${ }^{2}$ \\ ${ }^{1}$ Department of Mechanical Engineering, Delhi Technological University, Delhi, India \\ 1 aliamu200@gmail.com, ${ }^{2}$ sranidtu@gmail.com
}

\begin{abstract}
Metal foams are manufactured by various methods which include foaming of molten metal alloy and powder metallurgical processing. Some non conventional methods have also been developed for the manufacturing of metal foams. Metal foams have many interesting characteristics such as high resistance to deformation (stiffness), low specific gravity (specific weight), high resistance to compression and high energy absorption etc. Because of these characteristics metal foams find wide applications mainly in the field of construction where light weight is required, crash and impact energy absorption and in the field of thermal and sound insulation. Metal foams are cellular structure which consists of solid metal mainly (Aluminium, steels, iron etc) with micro pores filled with gas (hydrogen, carbon di oxide, nitrogen, argon etc). The metal foams are open cell or closed cell in nature. The gas comprises a large part of the volume of metal foam. In this review paper different methods for producing metal foam and their mechanical properties analysis are discussed especially for aluminium foam.
\end{abstract}

Keywords: Metal foam; Polyurethane; Auxetic foam; Investment casting; Foaming agent; Composite metal foam; Mechanical properties.

\section{Introduction}

The metallic foam of light weight metals have many interesting mechanical and physical properties including high resistance to deformation (stiffness), low specific gravity(specific weight), high compression strength, high toughness and energy absorption characteristics. Due to these interesting mechanical properties metal foams are utilized in wide range of applications. Various methods for the manufacturing of metal foams are illustrated in literature [1-5].In this paper different methods for the production of metal (aluminium) foams have been reviewed.

Different methods for production of metal foam are based on two main strategies. The first strategy includes direct foaming method in which foam is produced by gas injection or by mixing a foaming agent like titanium hydride into molten metal which contains uniformly dispersed nonmetallic particles. The second strategy includes indirect foaming method which starts from solid metal matrix which contains uniformly distributed blowing agent particles, mainly titanium or zirconium hydride. On melting, expansion of this metal matrix takes place and foam is produced. Due to promising future the researchers show their interest in the research of metal foam. Porous aluminium and its applications are shown in Fig. 1 
ISSN(Online) : 2456-8910

International Journal of Innovative Research in Applied Sciences and Engineering (IJIRASE)

Volume 3, Issue 11, DOI: 10.29027/IJIRASE.v3.i11.2020, 548-559, May 2020

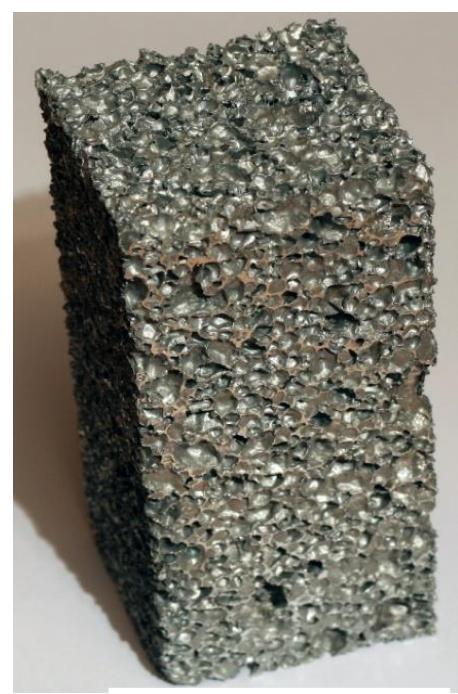

(a)

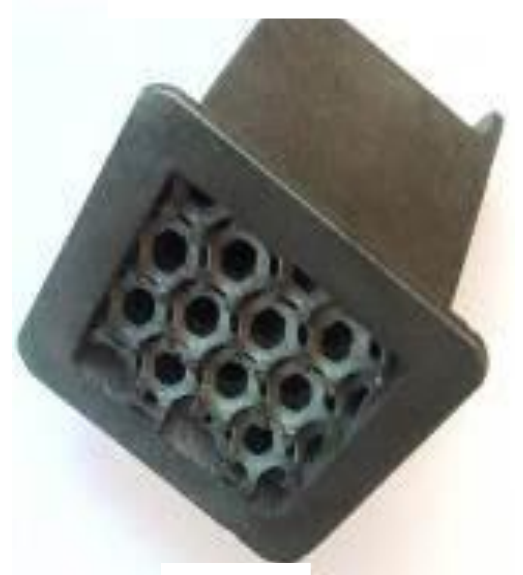

(b)

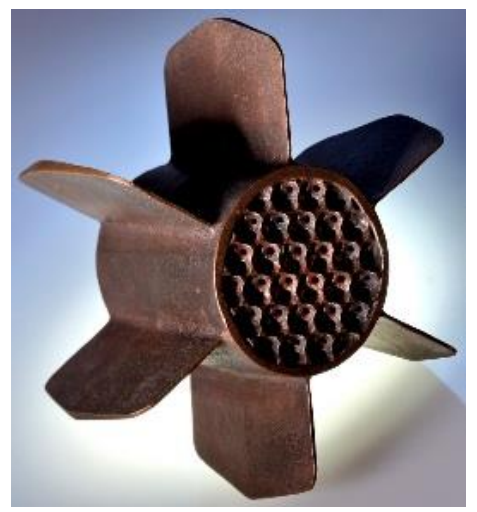

(c)

Fig. 1: (a) Al foamed structure (b) Metal foam heat sink (c) Header made of metal foam

\section{Early Research}

The metal foam fabrication started in the year 1940 AD. From 1950s to the 1970s a large number of patents were issued and various types of foaming processes were discovered and proposed. In late 1980s researchers re-established some of the old techniques of metal foam fabrication and discovered the new ones. In beginning, many companies carried out in house research in their laboratories and published their work. In year 1990, FraunhoferInstitute in Bremen worked in the field of metal foam fabrication and re-established old powder based technique of foam fabrication. At that time fundamental research was trying to compete the production process, which is already used in the industries. The main problem encountered was to understand how metal foams are stabilized and how its stability can be enhanced in order to prepare product of metal foam more reliable. The presence of non-metallic material particles ranging from nanometer to micrometer size like ceramics improves overall properties of metal foams. Binks et al. [7] have introduced the term high temperature colloid chemistry for the study of stabilization mechanism of metal foams in the field of aqueous foam physics. The second field is the investigation of mechanical properties of foamed metal and its structure. It was found that smooth cell wall metal foam is uniform in nature and yields the best mechanical properties. The properties of metal foam are described by a large number of morphological parameters such as density of metal foam and curvature, size, and orientation of the cell, cracks in cell walls, foam microstructure, grain size distribution, impurity level, ageing 
ISSN(Online) : 2456-8910

International Journal of Innovative Research in Applied Sciences and Engineering (IJIRASE)

Volume 3, Issue 11, DOI: 10.29027/IJIRASE.v3.i11.2020, 548-559, May 2020

conditions [2, 3] etc. Third is the modeling field and the modeling of metal foam structure is very crucial in order to analyze the data collected experimentally and to help engineers in the field of application of foamed metal. In modeling foam structure is usually depicted by a simple geometry and the foam is represented as an effective medium. Modeling of foamed structures on various levels had been attempted from micro-modeling to the modeling of entire component $[3,4]$. Beside these areas there are many other fields of research related to metal foam fabrication such as joining of foamed similar and dissimilar metals, cutting and coating of metal foams so as to attain desired properties. The introduction of new fabrication processes especially for Aluminium foam. Different types of filler materials can be mixed into the metal matrix in order to alter mechanical and physical properties of metal foams.

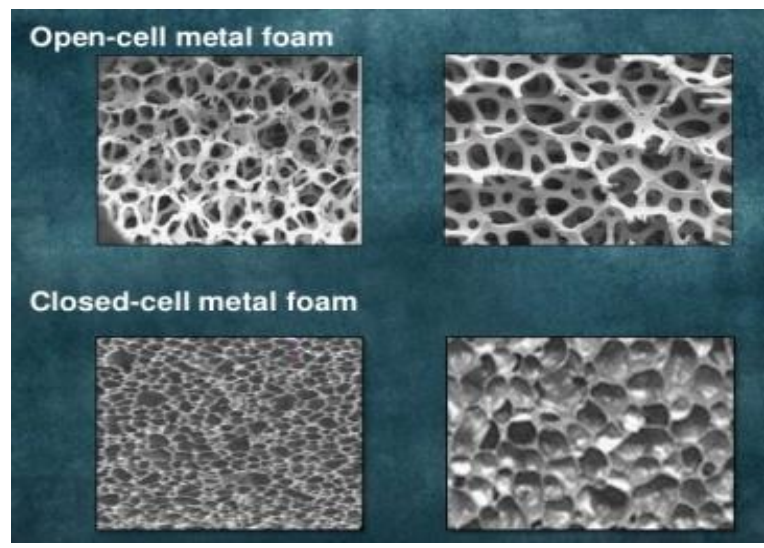

Fig. 2: Comparison between closed and open cell metal foam

\section{Literature Review}

Among all metal foam fabrication methods; there are two main methods of metal foam fabrication. One is the foaming of metal melt by injecting a gas in required proportion. The other method includes the mixing of foaming agent titanium hydride into the metal matrix and foaming occurs. There are a number of methods, which are utilized for the foaming of metal foams. However, most of the methods of metal foam fabrication are based on gas injection method or mixing of foaming agent method. Metal foam produced by different methods has many desired physical and mechanical properties and due to these mechanical properties metal foams are widely used in many applications. A detailed review of the metal foam fabrication methods with analysis of their mechanical properties is provided in this paper.

\subsection{Direct energy deposition method of metal foam} fabrication and mechanical properties analysis of produced foam

Koike et al. [8] have found that metal foams for stainless steel are fabricated by applying direct energy deposition (DED) method. Blowing agent titanium hydride $\left(\mathrm{TiH}_{2}\right)$ was blended into the alloy of stainless steel and the melt pool was foamed, this melt pool when solidified gives a foamed structure. By using this method small pores are observed while large pores could not be observed in a single layer deposition. By this method stainless steel foam of high porosity up to $46 \%$ was produced when melt was blended with calcium oxide and tellurium for single layer deposition. Further, the experiment results indicate that to obtain $40 \%$ porosity, 6 wt. $\%$ of titanium hydride is enough to foam the melt pool 
[8]. Table: 1 represents the composition by weight percent of ingredients required in direct energy deposition method. It was found that porosity of metal structure increased as the content ration of $\mathrm{TiH}_{2}$ increased and the same effect was found also with the laser power.

Table: 1 composition by weight percent of ingredients required in direct energy deposition method [8]

\begin{tabular}{|l|l|l|}
\hline Property of sample & $\begin{array}{l}\text { Single } \\
\text { layer }\end{array}$ & Six layer \\
\hline Laser power (w) & $\begin{array}{l}1200, \\
1600, \\
2000\end{array}$ & $\begin{array}{l}800, \\
1200,1600\end{array}$ \\
\hline Powder supply (g/min) & 18 & 18 \\
\hline Carrier gas supply (L/min) & 6 & 6 \\
\hline Shield gas supply (L/min) & 4 & \\
\hline $\begin{array}{l}\text { Nozzle feed rate (mm/min) } \\
\text { Titanium hydride (TiH2) ratio } \\
\text { wt\% }\end{array}$ & 1000 & 1000 \\
\hline $\begin{array}{l}\text { Calcium oxide (Cao) ratio } \\
\text { wt\% }\end{array}$ & 2,10 & $4,6,8,10$ \\
\hline Tellurium (Te) ratio wt\% & 0 & 1 \\
\hline
\end{tabular}

Fig. 3: Schematic of Direct Energy Deposition [8]

\subsection{Conventional polyurethane method for auxetic} foam fabrication and mechanical properties analysis of produced foam

Critchley et al. [9] have discovered that traditional polyurethane foam cells can also be represented as pentagonal and hexagonal structures. The pore structure is elongated and not symmetrical in nature. Polyurethane foams have either re-entrant or randomly ribbed structures and are auxetic in nature. In order to explain the auxetic behavior of polyurethane foam both the2D and 3D models were proposed. These models are classified as rigid triangle model, honeycomb model, missing rib model and bow-tie models.

The heating time ranging from 6 to $50 \mathrm{~min}$ has been reported [9].It has been reported that the heating time for auxetic fabrication ranges from 6 to 50 minutes and the optimum volumetric compression ratio is between 2 and 5 or between $50 \%$ and $80 \%$ of the original size [9].Auxetic materials have enhanced mechanical properties including hardness, toughness, stiffness and damping. The main factor that influences the auxetic behavior of foam is cell geometry and the second factor is pore size of the foam. Wang et al. [10] stated that small pore size foams require a high temperature with shorter heating time. 


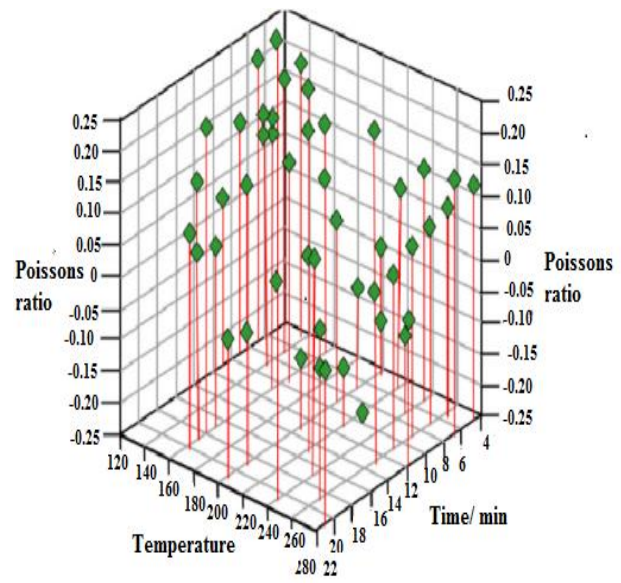

Fig. 4: Effect of 100 PPI manufactured samples under different conditions on Poisson's ratio [10]

Lakes et al. [11] have fabricated polymeric auxetic foam by altering the microstructural properties of the material. When tensile load is applied on auxetic materials they exhibit negative poisons ratio. They have made auxetic foam by protruding inward the ribs of each conventional open cell foam, which results in a re-entrant structure. Lakes et al. [11], yang et al. [12], chan et al.[13] have converted conventional foam into auxetic foam by tri-axially compressing open cell foam and then heating it to a temperature higher than the softening temperature of the material and then cooling it to room temperature in order to store potential energy in its ribs. The shape of cellular ribs got changed due to compression stage while simultaneous heating and cooling softened and fixed them in new position. Lakes et al. [11] have also observed that toughness of auxetic foam was also affected by its poison's ratio and established that material becomes extremely tough when Poisson's ratio reaches to the value of minus one $(-1)$.

Vol. 3 (11), May 2020, www.ijirase.com
Bianchi et al. [14] have modified method of polymeric foam conversion to auxetic foam. In this process of conversion, shape memory polymer (SMP) was used to reconvert polymeric foam to conventional foam and then converting it to auxetic foam. Evans et al. [15] established that uniform pressure distribution is proportional to $\left[\left\{\left(1-v^{2}\right) / E\right\}-1\right]$ for an isotropic material and for negative poison's ratio resistance to indentation increases towards infinity. The Fig. 5 clearly represents comparison between reaction of auxetic and conventional materials when subjected to hertzian indentation. Auxetic material has more hardness as compared to conventional material.

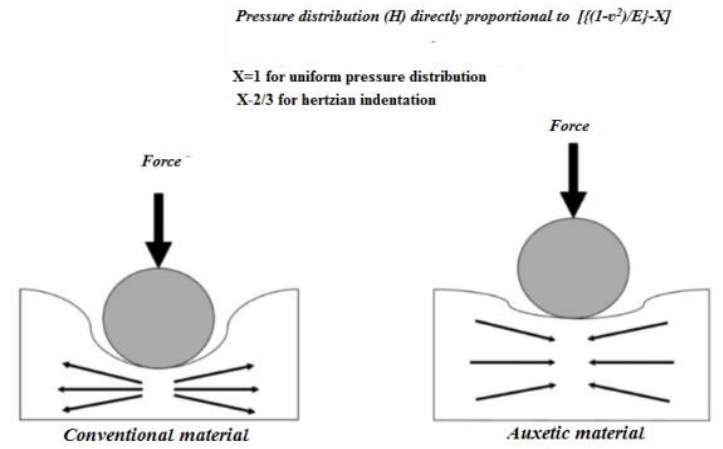

Fig.5: Reaction of conventional and auxetic material under hertzian indentation [15]

Grima et al. [16] have introduced a new method for fabrication of auxetic foams. This method comprises of chemo-mechanical process in which conventional polyurethane foam samples were compressed mechanically, the compressed samples were wrapped in filter paper and were kept in acetone for one hour and finally dried in the air. After complete drying the samples were removed from the moulds, the fabricated samples exhibited auxetic behavior and retained their compressed shape. The foam produced by this process was compared to foam produced by 
thermo mechanical process it was found that both the foams exhibited auxetic behavior with negative Poisson's ratio of approximately 0.3 .

Bianchi et al. [17] have fabricated auxetic foam by such a technique that density of auxetic foam can be changed to a large range. In this technique two batches of samples having different dimensions were placed into metallic mould and then compressed. The moulds were heated in an oven at $2008^{\circ} \mathrm{C}$ for a time period of 15,45 , and 60 minutes respectively. The moulds, which were preheated for 15,45 and 60 minutes were then heated to a temperature of $135^{\circ} \mathrm{C}, \quad 150^{\circ} \mathrm{C}$ and $1708^{\circ} \mathrm{C}$ respectively. The samples are then cooled. The foam samples which were heated for 15 minutes were cooled at room temperature for 5 minutes whereas the samples heated for 45 minutes and 60 minutes were removed instantly from moulds and then followed by cooling at room temperature. Due to this instant removal, the internal and external layers of the specimen have different microstructure. The external layer becomes stiffer and the inner layer becomes less dense. The time spent by the samples in the moulds is the basis for the densities of the fabricated samples. If the waiting time of the samples to be removed from moulds was longer, then densities of samples were found to be higher.

\subsection{Direct foaming of metal melts by gas injection} (air, nitrogen, argon etc.) and their mechanical properties analysis

Companies like Hydro Aluminium and Cymat have produced foams of aluminium and its alloys exploiting the process patented by researchers [1820].In this process aluminium matrix metal was melted and after that any one of the silicon carbide, aluminium oxide or magnesium oxide around 5 to 20 $\%$ was mixed into the melt to enhance its viscosity. Lloyd et al. [21] have also patented a process which resembles to this process. They produced ordinary metal matrix composites with homogeneous dispersion of reinforcing particles. After the addition of reinforcing particles into melt, foaming was done by using rotating gas impellers for blowing gases (air, nitrogen, argon etc) into the melt. The advantage of this process is to produce large volume of aluminium foam at low price with low density and porosities ranging from $80 \%$ to $97 \%$. Steps of direct foaming technique by gas injection are shown in Fig. 6 .

Prakash et al. [22] examined the closed cell structure foam made of aluminium matrix in compression and indentation. During compression test deformation localizes in a band and moves outward whereas during indentation localization, it occurs around the indenter and moves radially outward. The growth of cracks in the cell membranes is associated with a wide damage zone, resulting in high specific energy absorption capacity.

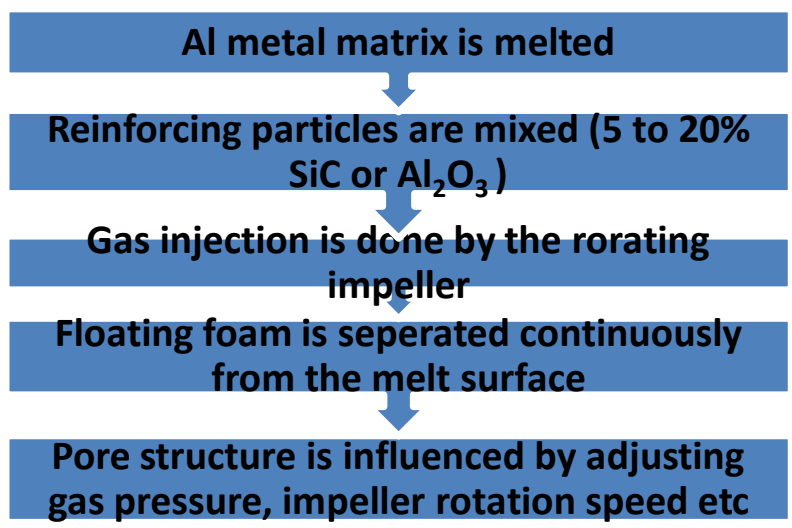

(a) 
ISSN(Online) : 2456-8910

International Journal of Innovative Research in Applied Sciences and Engineering (IJIRASE)

Volume 3, Issue 11, DOI: 10.29027/IJIRASE.v3.i11.2020, 548-559, May 2020

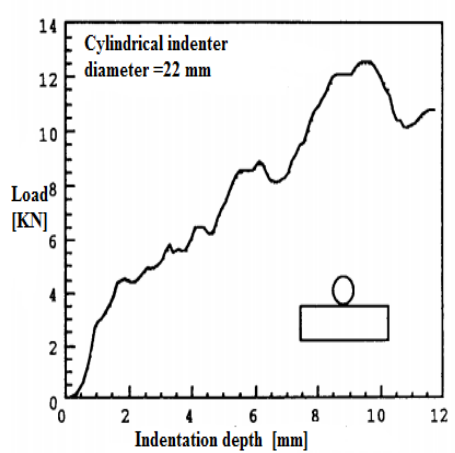

Fig.6: (a) Direct foaming of melts by gas injection (MMC foams) [21] (b) Load deflection response $\mathrm{Al}-\mathrm{SiC}$ foam [22]

3.4 Direct foaming of metal melts by foaming agent $\left(\mathrm{TiH}_{2}\right.$ etc) and their mechanical properties analysis

Akiyama et al. [23] have foamed melts directly by adding a foaming agent to the melt. On heating, foaming agent got decomposed and released gases which propelled the foaming process. This process is utilized in Japan for small production in which calcium is used to stabilize the metal and titanium hydride $\left(\mathrm{TiH}_{2}\right)$ as foaming agent. On heating, hydrogen gas is released which is further used for foaming the melt. The size of the foamed aluminium samples is approximately $2000 \times 1000 \times 600 \mathrm{~mm}$. The density of foamed samples varies from 0.25 to 0.33 $\mathrm{g} / \mathrm{cm}^{3}$. The foamed sample blocks were cut into sheets of varying thickness ranging from $5 \mathrm{~mm}$ to $250 \mathrm{~mm}$ [23].This process is well known as ALPORAS process and this method results into metal foam, which has uniform metal structure. Steps of ALPORAS process are shown in Fig.7. The pore structure of this type of metal foam was found to be more uniform and mechanical and sound absorption properties were measured.

\subsection{Solid-gas eutectic solidification process of metal foam fabrication (GASARS) and mechanical properties analysis of produced foam}

Shapovalov [24] has exploited the fact that some liquid metals form a eutectic system when they are in contact with hydrogen gas. In this process firstly the metal melts in an autoclave, which is pore free. After that hydrogen gas is dissolved into molten metal under high pressure usually at $50 \mathrm{~atm}$. At this stage the temperature and pressure is reduced and melt will went through two-phase field (solid plus gas) below the eutectic temperature. This gas fills the bubbles in the solid, which results in the foaming of melt. The pore structure obtained by this process is known as GASARS. This directional solidifying of the melt helps to fabricate foams containing large pores. Radial and axial pores are obtained by using cylindrical vessel [25]. The porosities ranging from $5 \%$ to $75 \%$ are achieved by this method and this method can be used to foam metals having medium and high melting points such as copper and nickel etc. The Steps of GASARS are shown in Fig.8

Simone et al. [26] have found that young's modulus and yield strength of porous copper samples increased linearly with the increase in its relative density however densification strain decreases linearly. 


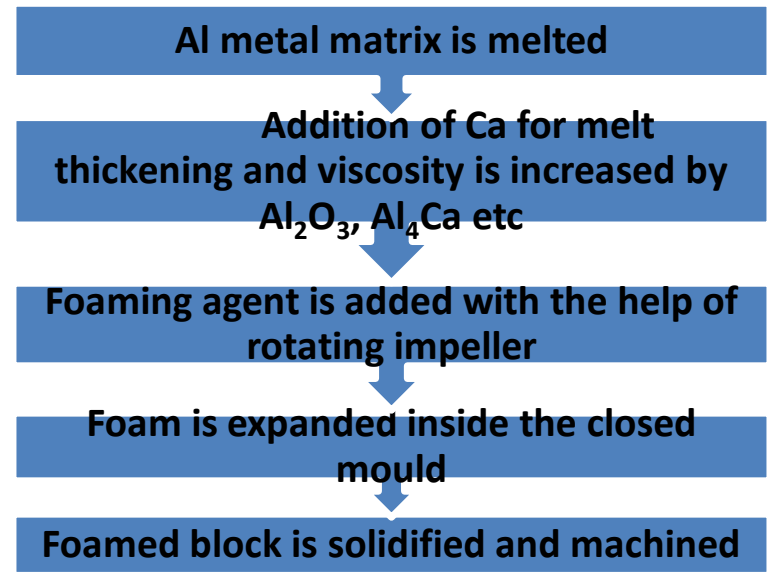

Fig.7: Direct foaming of melts by foaming agent (ALPORAS Process) [22]

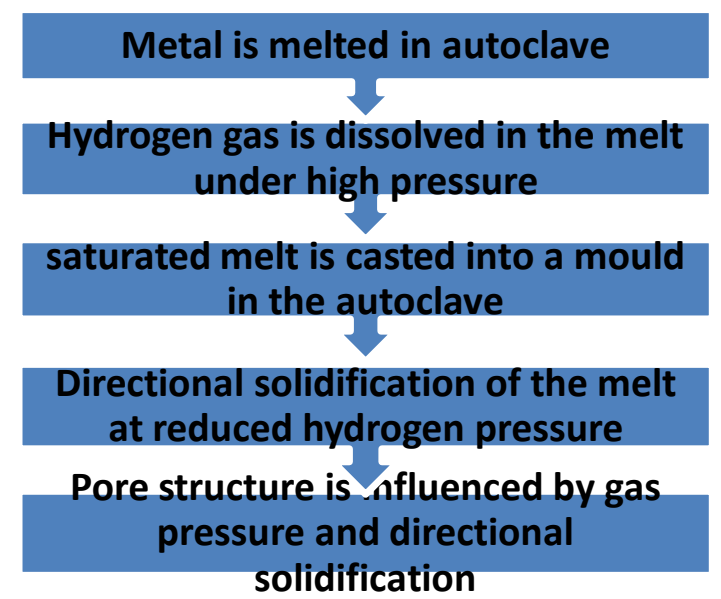

Fig.8: Foaming of metals by GASAR process [23]

3.6 Investment casting method of metal foam fabrication and mechanical properties analysis of produced foam

Yosida et al. [27] have fabricated metal foam by using polymeric foam. The polymeric foam was processed into open pore structure. These pores were filled by heat resisting materials like mixture of mullite, calcium carbonate and phenolic acid. When the slurry got dried the polymer was removed by heating and molten metal was poured into pores, which were left after polymer removal. Finally the mould material was removed and the metal foam was obtained, which is the exact replica of polymeric foam. The steps of this process are shown in Fig.9.The porosities of foam produced by investment casting ranges from $80 \%$ to $97 \%$.

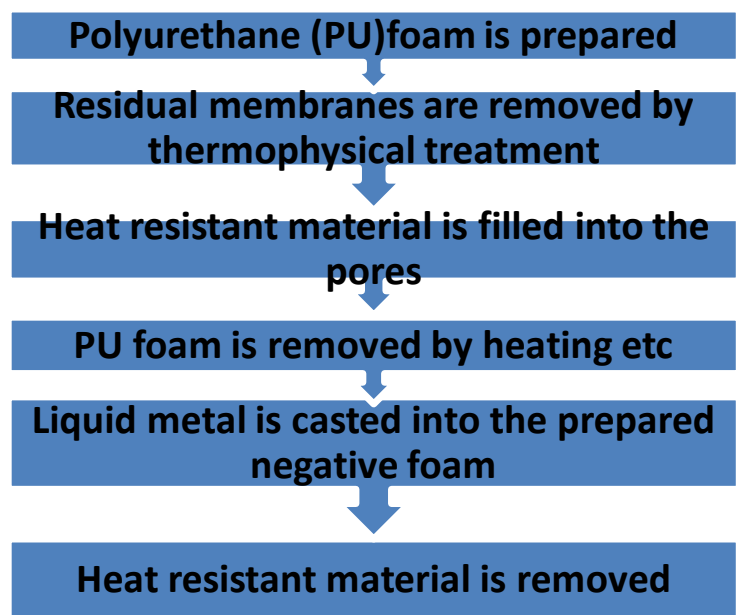

(a)

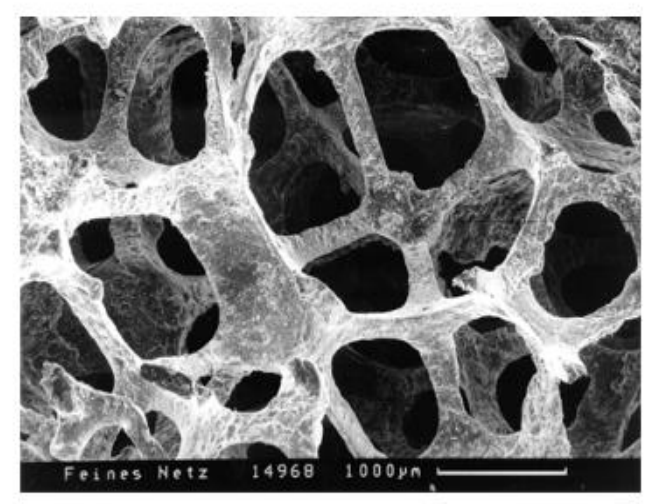

(b)

Fig.9: (a) Investment casting method and (b) SEM image [27]

3.7 Syntactic metal foam fabrication using filler materials and mechanical properties analysis of produced foam 
Thiele et al. [28] have produced porous metals by using inorganic particles as filler material. In this process foaming was done in two ways. In first case molten metal was poured over the filler particles and in second case filler particles were introduced into molten metal matrix. Since the thermal conductivity and heat capacity of filler particles was very low hence they allowed the flow of molten metal across the bulk easily. It was observed in this process that interstitial spaces were not completely filled by the molten metal due to high surface tension of molten metal. The filler particles which can be used in this process are foamed glass spheres of aluminium oxide, clay granules and hollow spheres. The advantages of this technique is that wide range of metals such as aluminium, lead, tin, zinc, magnesium etc can be foamed easily and predefined shape products can be prepared with the help of required mould geometry.

3.8 Powder metallurgy (PM) process for metal foam fabrication and property characterization

Baumeister [29] has produced foam by powder metallurgical method (PM) at Fraunhofer-Institute in Bremen. Aluminium metal or alloys were mixed with foaming agent and then the mixture was compacted. The compaction of mixture gives semi-finished metal foam in which the foaming agent particles were uniformly dispersed. This semi-finished foam was converted into sheets, rods and profiles etc. by rolling, extrusion and swaging etc. Now these processed sheets, rods etc were heated to a temperature above the melting point of the foam material and finished metal foam was obtained. The mechanical properties like density can be adjusted by controlling the volume of foaming agent other foaming parameters like temperature etc. Metal foams produced by this process have a porosity ranging $50 \%$ to $92 \%$. This method is best suited for foaming of tin, brass, zinc, lead, and bronze etc. The steps for powder metallurgical process are shown in Fig.10 and Fig.11 represents the pore structure.

\section{Foaming agent is mixed with powders}
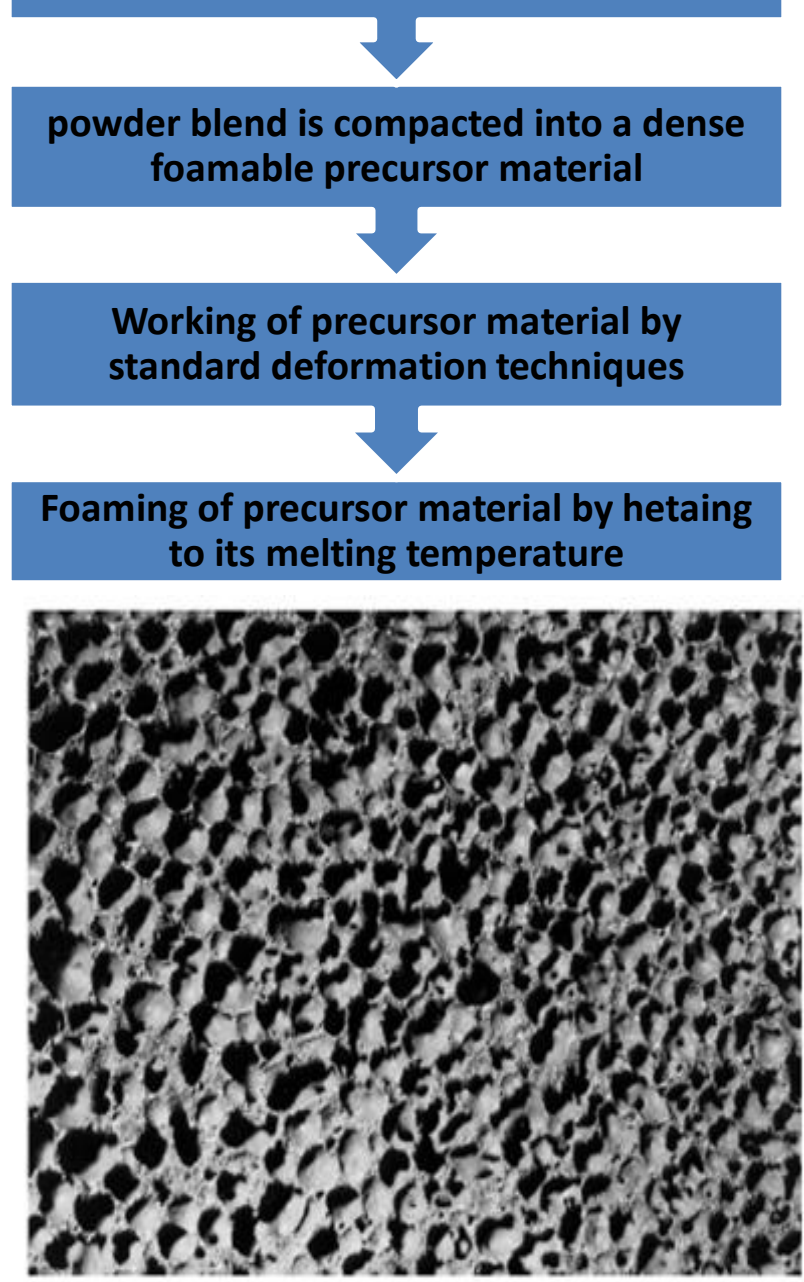

Fig. 10: Steps of powder metallurgical process [28]

Fig. 11: Pore structure of lead foam (Scale 4:1) [28] 
ISSN(Online) : 2456-8910

International Journal of Innovative Research in Applied Sciences and Engineering (IJIRASE)

Volume 3, Issue 11, DOI: 10.29027/IJIRASE.v3.i11.2020, 548-559, May 2020

\section{Conclusion}

In this paper different metal foams have been discussed and reviewed thoroughly mainly for $\mathrm{Al}$ foams. There are two strategies for metal foam production; one is the direct foaming method, in this process non-metallic particles are mixed and dispersed uniformly into the molten metal pool and foaming is done either by mixing blowing agent or directly injecting the gas (air, nitrogen, argon etc.) into the molten mixture. Second is the indirect foaming method, in this process initially a precursor material is prepared which is the mixture of aluminium matrix and uniformly dispersed blowing agent particles. On heating this precursor expands and foaming took place. All the fabrication processes developed and adopted by various researchers and companies respectively are based on these two foaming methods. New techniques of metal foam fabrication such as Direct Energy Deposition method, Conventional polyurethane method for auxetic foam fabrication, solid-gas eutectic solidification process of metal foam fabrication (GASARS), Investment casting method of foam fabrication, syntactic foam production with filler materials, entrapped gas method of foam fabrication, metal deposition method, chemical vapor deposition method etc are also reviewed thoroughly. It was observed that metal foams have superior physical and mechanical properties than their parent metal such as stiffness, compressive strength, tensile strength, proof stress, sound absorption quality and specific energy absorption capacity etc. due to these promising characteristics metal foams are widely used in automotive, aerospace and defense applications.

\section{Future scope}

(1) As the literature review indicates that the metal foams are being manufactured by various conventional methods. New methods are developed and employed to fabricate metal foams such as shell mould casting method can be utilized to prepare metal foam with the help of polymeric foams.

(2) Optimization of heating time should be done for auxetic foam as optimum heating time has not been optimized, however a range of 6 to 50 minutes has been recorded.

(3) The foams prepared lacks in stability and are not of constant quality. There is lack of control on structure and morphology of metal foams. Hence, existing methods should be improved in order to obtain good quality foams.

(4) Cost- effective methods should be employed for metal foam fabrication which is suited for a high volume mass production.

(5) Searching for more effective reinforcing particles such as carbon nanotubes, carbon fibers, ceramic particles, short fibers etc. should be continued. Efforts should be made to develop methods for more uniform distribution of reinforcing agents.

(6) Focus on development of metal foams having better mechanical properties such as high compressive strength, high stiffness, toughness etc.

(7) Metal coating of foams may be done to enhance mechanical properties. 


\section{(8) References}

[1] Banhart J (2001) Manufacture, characterization and application of cellular metals and metal foams. Progress in materials science 46(6): 559-632.

[2] Banhart J, Ashby M, Fleck N (1999) Metal foams and porous metal structures. Conference on Metal Foams and Porous Metal Structures $14: 16$.

[3] Esmaeelzadeh S, Simchi A, Lehmhus D (2006) Effect of ceramic particle addition on the foaming behavior, cell structure and mechanical properties of P/M AlSi7 foam. Materials Science and Engineering: A 424 (1-2): 290299.

[4] Banhart J, Seeliger HW (2008) Aluminium foam sandwich panels: manufacture, metallurgy and applications. Advanced Engineering Materials 10(9): 793-802.

[5] Degischer, Peter H, Kriszt B (2002) Handbook of cellular metals: production, processing, applications. Wiley-vch.

[6] Banhart J, Weaire D (2002) On the road again: metal foams find favor. Physics Today 55(7): 37-42.

[7] Binks, Bernard P, Tommy S (2006) Book on Colloidal particles at liquid interfaces. Cambridge University Press.

[8] Koike R, Matsumoto T, Kakinuma Y, Aoyama T, Oda Y, Kuriya T, Kondo M (2018) A basic study on metal foam fabrication with titanium hydride in direct energy deposition. Procedia Manufacturing 18: 68-73.

[9] Critchley R, Corni I, Wharton JA, Walsh FC, Wood RJ, Stokes KR (2013) A review of the manufacture, mechanical properties and potential applications of auxetic foams. Physica status solidi 250(10): 1963-1982.

[10] Wang YC, Lakes R, Butenhoff A (2001) Influence of cell size on reentrant transformation of negative Poisson's ratio reticulated polyurethane foams. Cellular Polymers 20(6): 373-385.

[11] Lakes R (1987) Foam structures with a negative Poisson's ratio. Science 235: 1038-1041.

[12] Yang W, Li ZM, Shi W, Xie BH, Yang MB (2004) Review on auxetic materials. Journal of materials science 39(10): 3269-79.

[13] Chan N, Evans KE (1997) Fabrication methods for auxetic foams. Journal of Materials Science 32(22): 5945-5953.

[14] Bianchi M, Scarpa F, Smith CW (2010) Shape memory behavior in auxetic foams: mechanical properties. Acta Materialia 58(3): 858-865.

[15] Evans KE, Alderson A (2000) Auxetic materials: functional materials and structures from lateral thinking. Advanced materials 12(9): 617-628.

[16] Grima JN, Attard D, Gatt R, Cassar RN (2009) A Novel Process for the Manufacture of Auxetic Foams and for their reconversion to Conventional Form. Advanced Engineering Materials 11(7): 533-535.

[17] Bianchi M, Frontoni S, Scarpa F, Smith CW (2011) Density change during the manufacturing process of PU-PE open cell auxetic foams. physica status solidi 248(1): 30-38.

[18] Jin I, Kenny LD, Sang H, US Patent 4,973, 358 (1990), PCT Patent WO 91/03578 (1991) PCT Patent WO 
92/03582 (1992), US Patent 5,112, 696 (1992).

[19] Thomas M, Kenny LD, PCT Patent WO 94/172218 (1994).

[20] Ruch W, Kirkevag B, PCT Patent WO 91/01387 (1991).

[21] Lloyd DJ, Mc Leod AD, Morris PL, Jin I, PCT Patent WO 91/19823 (1991).

[22] Prakash O, Sang H, Embury JD (1995) Structure and properties of Al \& $\mathrm{SiC}$ foam. Materials Science and Engineering: A 199(2): 195-203.

[23] Akiyama S, Ueno $H$, Imagawa $K$, Kitahara A, Nagata S, Morimoto K, Nishikawa T, Itoh M (1987) Foamed metal and method of producing same. United States patent US 4,713,277.

[24] Shapovalov VI, US Patent 5, 181, 549 (1991).

[25] Zheng Y, Sridhar S, Russell KC (1995) Advances in Porous Materials. In MRS Society Bull 371: 365.

[26] Simone AE, Gibson LJ (1997) The compressive behavior of porous copper made by the GASAR process. Journal of materials science 32(2): 451-457.

[27] Yosida Y, Hayashi C (1990) Proceedings of Conference Casting science and technology : 103.

[28] Thiele KH (1972) A contribution to the chemistry of organo transition metal halides. Pure and Applied Chemistry 30(3) (4): 575-586. 